\title{
"AS ALEGRIAS DO DEVER", TEMA DE UMA AULA DE ALEMAO DE SIEGFRIED LENZ
}

\section{Petra Bossmann Romanus *}

$O$ presente trabalho representa uma contribuição ao estudo da obra de Sicgfried Lenz Aula de alemão (Deutschstuned), que focaliza muitos problemas de ordem moral, psicológica e social.

Através de toda a obra situa-se como motivo principal o conceito do dever, que na redação de Siggi - As alegrias do dever - encontram sua significação.

A ação situa-se nos últimos anos da Segunda Guerra Mundial ¿ no início da República Federal da Alemanha.

Os personagens principais, antagonistas, são o policial de Rüggbüll, Jens Ole Jepsen e seu filho Siggi Jepsen.

O conflito inicia-se com a proibição de trabalho do pintor Max Ludwig Nansen, tido no regime nacional socialista como "degenerado", porque considerava um dever exprimir nas suas pinturas de uma maneira estranha. fantástica o protesto contra o regime dominante.

Apesar da amizade existente entre o policial e o pintor Nansen, oito anos mais velho do que aquele, e que o havia salvo da morte por afogamento, na sua juventude, considerava o policial, como sendo seu dever, de fiscalizar essa proibição. Seu filho Siggi é encarregado de ajudá-lo nessa tarefa de controle, e. na sua maneira infantil, inicialmente. não leva a sério o encargo, e é por isso, conivente com o pintor. Com o passar dos anos desenvolve-se nele consciente cumprimento do dever, e reconhece a progressiva atitude doentia de seu pai. Para salvar as pinturas da demência destruidora do pai, esconde-as num velho moinho, mesmo com medo e angústia de ser descoberto. Como o pai prossegueia na destruição das pinturas de Nansen. mesmo após a queda do nacional-socialismo, desenvolveu-se também em Siggi, a demência, como reação interior. Como sua manifes-

- A autora. Licenclada em Letras Anglagermanicas pela Universidade Federal do Paraná. realizou de 1965 a 1967. Curso de Aperfelcoamento em Ingun e Literatura Alema em Kassel e Colonla (Alemanha). Publicou no N.d 20 dn Revista Letras, 1972, o trabalho Aspectos da vida de Gerhart Hauptmann. Atualmente e Auxlliar de Ensino da disciplina de Língua e Literatura Alema. 
taçāo, cle se sente obrigado de tomar sob custódia os quadros de Nansen, mesmo quando isto não era mais necessário.

Deste modo, o anteriormente protetor das obras de arte é considerado no julgamento de outros um ladrāo, e deve, por ironia do destino, cumprir pena em uma escola correcional de Hamburgo. Aí The é dado, então, como castigo, na aula de alemāo, a redação sobre o tema "As alcgrias do dever".

Esta introdução torna-se mister para a compreensão do tema propriamente dito.

Existe pouco a constatar na redaçāo de Siggi acerca das alegrias do dever, exceto talvez a alegria macabra que ele notou no pai, quando este queimou os documentos:

Uma expressão de animalesca satisfaçāo resplandecia no seu rosto, agora que ele o realizou, pode permanecer calmc c fumar como após uma missão cumprida...1

Teria então Siggi falhado na realizaçāo de seu tema de redaçāo? O que é o dever? Para qual compreensão do dever quer-nos Siegfried Lenz dirigir em seu romance? O dever pertence certamente ao traço de personalidade dos alemães. A pratica diária do dever para a qual 's rei da Prússia Friedrich Wilhelm I (1688-1740) educou seus funcionários, são acrescentadas reflexōes ético-filosóficas, especialmente de Immanuel Kant. contemporâneo de Friedrich Wilhelm I "Imperativ. Categórico", e de Friedrich von Schiller. Influências da filosofia de Kant podem também ser notadas em Heinrich von Kleist na obra Prinz von Homburg. Seria interessante pesquisar se, e até que ponto. o procedimento do rei Friedrich Wilhelm I influenciou a filosofia de Kant sobre o conceito do dever.

Quando se reconhece no decorrer da ação do romance, que consequiências tem o obstinado cumprimento do dever, nāo causa surpresas. se o tema do trabalho forçado de Siggi quase que desapercebidamente toma outro caráter: não mais as "alegrias do dever constituem o ponto central. mas sim as avifimas do dever 2. Siggi exprime isto em diálogo com seu guarda Joswig:

Vê você, perguntou ele. reconhece para onde alguém pode ser arrastado pelas alegrias do dever? $O$ que elas são capazes de fazer de alguém?... Disse eu: Estas são as alegrias do dever, como Korbjuhn, o professor de alemão, as queria; dife rente sāo suas vitimas; delas ninguém lembra. 3

Jens Ole Jepsen é o tipo característico de um funcionário prussiano. que representa a encarnação do maldito dever a exercê-lo em primeiro plano. Afirma-se que ele atua humanamente quando retira o seu uniforme, mas quando o veste identifica-se com o seu dever.

1 LENZ. Biegfried. Deutschstunde. Hamburg. Hoffmann und Campe, 1968. p. 574.

3 PEINERT, Dietrich. Slegfrled Lenz'Dentsehstunde. Hamburg. Hoffmann und Campe. 1973. p. 172

3 LENZ, p. 365 . 
O Estado de Direito desacostumou o indivíduo de tomar decisōes pessoais na vida política. Deve ser o certo aquilo que foi decidido em inståncia superior. Isto persistiu assim, mesmo quando o Estado totalitário substituiu o velho sistema. Estava-se acostumado à obediência cega, a uma renúncia absoluta da própria vontade. $\mathrm{E}$ assim da virtude coletiva do cumprimento do dever, que durante tanto tempo comprovou sua eficiência na manutenção e progresso do Estado. originou-se uma culpabilidade coletiva. O "Führer" ordenou! Para muitos que prestaram depoimento perante o tribunal de Nürnberg. valia como desculpa: Somente cumpri com o meu dever!

"Quem apenas realiza mecanicamente sua obrigaçăo, jul* ga-se dispensado do compromisso de preocupar-se com as consequiências de seu modo de agir. Neste sentido torna-se a frase - "Quem cumpre seu dever, não precisa ter preocupações, mesmo se os tempos uma vez mudarem" 4 - num sinal para o perigo, que pode existir no conceito do "cumprimento do dever" 5 .

Em magistral técnica narrativa descreve Siegfried Lenz a lenta metamorfose do policial no próprio dever. Inicialmente ele transmite com relutância interior a proibição de trabalho artístico ao amigo da juventude:

Eu não imaginei tudo isto, Max, podes acreditar-me. Com a proibição do trabalho, nada tenho a ver; cabe-me apenas transmitir-lhe. Eu sei, respondeu o pintor. e, ademais, estes dementes, como se não soubessem, isto é impossível: a proibiçāo de pintar. Poder eles talvez conseguir muito com os seus meios; podem evitar muitas coisas pode ser, mas nāo isto; que alguém pare de pintar. Isto já outros tentaram, muito antes deles e precisam apenas investigar: contra quadros indesejáveis nunca houve proteção nenhuma, nem mesmo a cegueira, nem tampouco o exilio, e, se mandassem amputar as mãos, pintar-se-ia então com a boca. Estes tolos. como se não soubessem, também existem quadros invisiveis!

A mim, Max, eles me ordenaram fiscalizar a proibição de pintura, e que você também saiba disso. A você? perguntou o pintor, e meu pai replicou: A mim. sim, que eu sou o mais chegado.

Eles se entreolharam, um sentado, o outro de pé. Fitaram-se em silêncio por um instante, lembraram-se possivelmente dos conhecimentos que um possuía do outro, e imaginaram como eles se iriam relacionar em futuro próximo e assim por diante, pelo menos perguntaram-se com quem de agora em diante eles teriam de contar, quando eles se encontrassem aqui ou ali...6.

Assim mostrou-se o policial mais tarde reservado e inacessível:

Meu pai comportou-se diante do pintor sem constrangimento; foi-lhe possivel até demonstrar em sua atitude um anseio

4 LENZ, p. 109

5 PEINERT, p. 166.

6 LENZ, D. 35.6. 
impaciente. Isto reconheci sem dificuldade, e não fiquei surpreso, quando ele disse: Foi decidido em Berlim, isto basta. Você mesmo leu a carta. Max. Devo intimá-lo a comparecer à seleçāo dos quadros. Vocè quer prender os quadros? perguntou-lhe o pintor. Ao que meu pai respondeu seco e sem contemplação: Nós vamos verificar que quadros devem ser recolhidos. Eu anoto tudo, para que eles possam ser apanhados amanhã. Vocês não sabem mais o que fazem, disse o pintor. e, entāo, meu pai deixou escapar a frase: "Eu apenas cumpro o meu dever, Max. 7

Com um quadro cômicogrotesto Siegfried Lenz tornou claro a postcrior identificação entre dever e inclinaçāo em Jens Ole Jepsen. O que é inicialmente simples execução de uma ordem, tornou-se uma determinação interior deste ser humano. A procura de quadros transformou-se em mania, a qual o autor concretiza, dotando o policial de um dom profético, chamado "segunda face.

Jens Ole desenvolveu em repentinos estados de transe uma capacidade parapsicológica de olhar o futuro: um quadro tétrico, macabro para a perspicácia detetivesca, com a qual um quase demente procurou. encontrou e destruiu obras de arte. Com isso atroficu cada vez mais o sentimento humanitá. rio desse homem. A obsessão pelo cumprimento do dever destruiu o núcleo humano, de modo que tal ser apenas exteriormente é mantido através de seu uniforme. 8

Quando se observou a evoluçāo posterior do policial, depreendeu-se que, apesar do periodo da desnazificação, ele não se modificou, mesmo tendo sido suspensa a proibiçāo do trabalho artístico. Passou ele a qucimar documentos sigilosos e tentar também destruir uma pasta. apreendida, de esboços do pintor, sem possuir para tal qualquer ordem. Obedeceu a partir de agora a uma voz interior, a qual traiu sinais de demência.

Vítimas deste mesmo delírio foram também amigos e familiares. O papel de Jepsen é complexo. Que ele se entregou a uma força do mal, é compreensível, e, por outro lado ,o papel do pintor é também dificil. O romance indica que nem todos os artistas são dotados da qualidade de Nansen. isto é, de defender sua independência.

A Siegfried Lenz interessa a substância do povo alemão. Se persistir no povo o velho conceito do dever, está sempre presente o perigo, que se repita a tragédia de um regime totalitário.

A quintessència desse romance nos dá Kenneth Eltis de uma maneira bem sucedida em Slegfried Lenz und dle Polltik:

O que condena neste conflito a policial Jepsen e justifica o pintor Nansen, é o princípio da responsabilidade individual o tema principal nas últimas obras de Lenz. O sistema do poder no qual ele se enquadrou, é impessoal, a origem das ordens é difícil de identificar.

7 LENZ, p. 78.

8 PEINERT, D. 166. 
A força do sistema está na sua monstruosa anonimidade, e sua força de atração consiste em que o sistema possibilita ao mais insignificante de seus membros exprimir a responsabilidade de suas açōes, concedendo-lhes ao mesmo tempo a autoridade. Ele expōe um código bem - soante de conceitos abstratos sobre dever, obediência, serviço - e os utiliza para justificar qualquer açāo, que ele cmpreende para assegurar a sua posição. Homens como Jepsen, que seguem o ideal do sistema e nunca perguntam por sua validade, nem sequer analisam as açōes, as quais são obrigados a executar em nome da autoridade, sāo simultancamente servidores, mantenedores e vítimas do sistema. Artistas, homens como Nansen, ameaçam o sistcma, enquanto eles persistem em somente servir tais ideais, que eles próprios estabeleceram e elegram, os quais, além disso, pla sua atitude estāo preparados para assumir a responsabilidade pessoal, que seus ideais exigem de si, para falar pelas vítimas do dever, pelos homens que nāo podem "ver" e estão condenados ao silêncio.

Este conflito que se desenrola em tempo de guerra entre dois pontos-de-vista a respeito do dever, já em si é significativo. Lenz lhe atribui ainda maior importância. no qual ele o torna como ponto de partida para os atuais (1954) problemas do nar. rador. Siggi Jepsen mostra que o passado nāo se deixa superar tão facilmente. Não ¿ possivel através de um curto programa de formaçāo após-guerra, fazer desaparecer o prejuízo que foi causado a Jepsen pela ditadura durante a guerra.

Ele nunca abandonou seu comportamento fanático; poderia tornar-sc novamente, a qualquer tempo, um servidor de qualquer sistema de governo, o qual apelasse a sua "prontidão demonstrada por suas manifestaçōes exteriores que se originaram pelo costume [...]

Aula de alemão mostra, que a pior forma de violência que um estado totalitário pode exercer, é a opressão da liberdade de pensamento. Lenz demonstra na sua obra que também após a queda do regime nazista alguns dos outrora válidos ideais ainda estāo vivos. 9

Poderia ser lembrada aqui a sentença usada por Bert Brecht no epílogo da sua obra A Boa Alma de Sezuan: "Nós mesmos ficamos decepcionados e vemos, em consternação, a cortina fechada e todas as perguntas no ar".

REFWRENCLAS BIBLIOGRAFICAS

LENZ, Siegfried. Deutschstunde. Hamburg. Hottman und Campe, 1968, 480 p. PEINERT, Dietrich. Slegfried Jenz Deutschstunde. Hamburg, Hoffmann und Campe, 1973. 272 D.

\section{Resumo}

O autor pretende esclarecer e fazer o povo alemāo refletir sobre - enferrujado conceito do cumprimento do dever com base nas experiências vividas durante o nazismo. Assim, torna-se a Aula de Alemão uma lição para todo o povo alemão. Este conceito, o autor tenta

9 PEINERT, p. 90-1. 
representar nos personagens principais da obra que são o policial Jens Ole Jepsen, seu filho Siggi Jepsen e o pintor Max Ludwig Nansen.

\section{Zusammenfassung}

Dem Verfasser scheint es darum zu gehen, dem deutschen Volka aus den Erfahrungen der Nazizeit den eingerosteten Begriff der Pflichterfüllung zu klären und zu überdenken. So wird die Deutschstunde zu einer Lektion tür das ganze deutsche Volk. Diesen Begriff versucht der Autor, an den Hauptpersonen des Werkes, Polizeiposten Jens Ole Jepsen, seinem Sohn Siggi Jepsen und dem Maler Max Ludwig Nansen darzustellen. 